\title{
Toevoeging van nieuwe linguïstische en communicatieve maten binnen de huidige ASTA
}

\author{
Elsbeth Boxum ${ }^{1}$, Fennetta van der Scheer ${ }^{2}$, Nely van Werven $^{3}$, \\ Wencke Dirksen ${ }^{4}$, Roel Jonkers ${ }^{5}$ \\ ${ }^{1}$ Vogellanden, Centrum voor Revalidatie, Zwolle \\ ${ }^{2}$ Amsterdam UMC, Vrije Universiteit, KNO/hoofd-halschirurgie, Amsterdam \\ ${ }^{3}$ Advies- en Behandelcentrum van Zorggroep Noordwest Veluwe, Harderwijk \\ ${ }^{4}$ Zorggroep Charim, Veenendaal \\ ${ }^{5}$ Afdeling Taalwetenschap, Rijksuniversiteit Groningen
}

\begin{abstract}
Samenvatting
Klinisch linguïsten gebruiken in de diagnostische fase voor de beoordeling van de spontane taal bij afasie veelal de Analyse voor Spontane Taal bij Afasie (ASTA). Het meest recente ASTA-protocol uit 2013 bestaat uit twaalf linguïstische taalmaten. In dit artikel worden twee kleinschalige en exploratieve onderzoeken naar zestien nieuwe communicatieve en linguïstische taalmaten beschreven. De onderzoeksvraag hierbij is, in hoeverre deze taalmaten een waardevolle toevoeging zouden kunnen zijn op de huidige ASTA maten. De uitgevoerde groepsvergelijkingen met de nieuwe maten tonen aan dat mensen met afasie significant afwijkend scoren op de maten 'woorden exclusief linguïst', 'pauzes', 'valse starts', 'onvolledige uitingen', 'geëxcludeerde woorden', 'relevantie antwoord', 'stereotypen', 'koppelwerkwoorden' en 'bijvoeglijke naamwoorden' ten opzichte van gezonde taalsprekers. In de discussie zal verder ingegaan worden welke van deze negen maten daadwerkelijk klinisch relevant zijn om toe te voegen aan de huidige maten van de ASTA. Met meer maten kan, indien nodig, de spontane taal bij mensen met afasie specifieker geanalyseerd worden waardoor een meer op maat behandeladvies mogelijk is.
\end{abstract}

\begin{abstract}
Summary
The analysis for spontaneous language in aphasia (ASTA; Boxum, Van der Scheer \& Zwaga, 2013) is the official Dutch protocol for analysing spontaneous speech. At the moment, the ASTA includes twelve linguistic measures. This paper describes the outcomes of two explorative studies to the necessity of adding new linguistic and communicative measures. In comparing aphasic and non-language disturbed speakers considering these
\end{abstract}

Correspondentieadres: Elsbeth Boxum, Logopedist/klinisch linguïst. Vogellanden Centrum voor Revalidatie. Hyacinthstraat 66A, 8013 XZ, Zwolle.

E-mail: e.boxum@vogellanden.nl 
new measures it was found that speakers with aphasia produced a significantly lower number of words per minute and a higher number of pauses than the control speakers. In the aphasia group, also a significantly higher number of false starts, a higher number of incomplete expressions, a higher number of excluded words, a lower number of relevant answers, a higher number of stereotypes, a lower number of adjectives, and a lower number of linking verbs were found. It will be discussed that some of these measures are relevant to be included in the ASTA. Also, having more measures to use, the therapy advice for speakers with aphasia can be made more specific.

\section{Inleiding}

Een stoornis in de spontane taal is het meest opvallende kenmerk van een afasie (Van der Scheer, 2009; Vermeulen \& Bastiaanse, 1984). Om de spontane taal bij mensen met afasie te onderzoeken wordt er in Nederland gebruik gemaakt van de Analyse voor Spontane Taal bij Afasie (ASTA) (Boxum, van der Scheer en Zwaga, 2013). De ASTA is in samenspraak met de Vereniging voor Klinische Linguïstiek (VKL) tot stand gekomen en verscheen voor het eerst in 2005. Sinds die tijd zijn er enkele vernieuwde versies uitgebracht. De laatste versie van de ASTA dateert uit 2013 en wordt binnen de klinische linguïstiek thans veelvuldig gebruikt. De analyse van het spontanetaalsample levert informatie op over het functioneren van de patiënt met afasie op de verschillende linguïstische niveaus, zoals fonologie, semantiek en morfosyntaxis (Prins \& Bastiaanse, 2004). Aan de hand van een dergelijke taalanalyse kunnen goede aanknopingspunten voor vervolgonderzoek en therapie gegeven worden. Tenslotte kunnen veranderingen van de mondelinge taalproductie in de tijd worden vastgelegd en kan een therapie-effect worden vastgesteld.

In dit artikel worden twee kleinschalige en exploratieve studies besproken.

Studie 1 onderzoekt tien communicatieve maten die ingedeeld kunnen worden onder vloeiendheid in het spreken, gerichtheid in het spreken en geautomatiseerde taal. In een kwalitatieve beschrijving van de spontane taal beschrijft de klinisch linguïst hoe de communicatie verloopt, maar zij mist momenteel kwantitieve maten ter onderbouwing hierbij. De huidige ASTA voorziet bijvoorbeeld niet in het wel of niet vaststellen of de afasie vloeiend of niet vloeiend is. Hierom is gekozen om vijf maten die de vloeiendheid in kaart kunnen brengen nader te onderzoeken. De ASTA biedt inzicht in het lexicale, fonologische en syntactische functioneren van de persoon met afasie, maar niet of de talige inhoud kloppend is. In studie 1 worden verder twee maten bekeken rondom de gerichtheid in het spreken. Aangezien er nog geen maten beschikbaar zijn binnen de ASTA rondom de geautomatiseerde taal, zal in de huidige studie zal daarom gekeken worden naar zowel de taalautomatismen, als de stereotypen en echolalieen.

Studie 2 onderzoekt vier nieuwe linguïstische maten, waardoor mogelijk een duidelijkere uitspraak gedaan kan worden over de lexicale vaardigheid van de patiënt. Het gaat hierbij om twee verschillende soorten voorzetsels, de bijvoegelijk naamwoorden en de bijwoorden. Hiernaast wordt bekeken of het opsplitsen van de al bestaande maat 'koppelwerkwoorden 
en modale (hulp) werkwoorden' zinvol is, zoals in een eerdere studie is aanbevolen door Van der Scheer (2009).

In beide studies staat de onderzoeksvraag centraal in hoeverre de zestien voorgestelde taalmaten een waardevolle toevoeging zouden kunnen zijn op de huidige ASTA maten. De eerste stap hiervoor is het vergelijken van de taalproductie van mensen met verschillende vormen van afasie met de taalproductie van gezonde proefpersonen. Indien personen met een afasie op bepaalde maten hetzelfde zouden scoren als gezonde taalsprekers, dan leveren deze maten geen meerwaarde op om de afatische taal in kaart te brengen en hoeven deze niet opgenomen te worden in het huidige ASTA-protocol. Als tweede stap zal vervolgens per significant bevonden maat de klinische relevantie bekeken moeten worden. De onderzoeksvraag uit beide studies is onderzocht aan de hand van de verwachting dat de patiëntengroep op alle taalmaten significant slechter scoort dan de controlegroep.

\section{ASTA}

De studies in dit artikel bieden mogelijk extra taalmaten naast de bestaande linguïstische taalmaten binnen het huidige ASTA-protocol. Het huidige protocol van de ASTA biedt op structurele wijze hulp in de analyse van een sample spontane taal, uitgelokt door een aantal standaardvragen. Deze vragen zijn afgeleid van de vragen die gesteld worden bij de opname voor de Spontane Taal van de Akense Afasie Test (Graetz, de Bleser en Willmes, 1992) te weten:

- Kunt $\mathrm{u}$ mij vertellen wat er met $\mathrm{u}$ is gebeurd?

- Wat voor beroep heeft u (gehad)? Kunt u daar wat over vertellen?

- Kunt $\mathrm{u}$ iets vertellen over uw familie?

- Heeft u hobby's/ wat doet u graag in uw vrije tijd?

De vragen worden in bovenstaande volgorde gesteld en er dienen tenminste drie onderwerpen aan bod te komen. In totaal wordt een sample van 300 woorden geanalyseerd. De ASTA kan bij patiënten met verschillende typen afasie worden toegepast, mits het mogelijk is 300 woorden spontane taal uit te lokken. Op basis van de twaalf taalmaten kan er een uitspraak gedaan worden over de morfosyntactische, semantische en fonematische vaardigheden van de persoon met afasie. In tabel 1 worden deze linguïstische niveaus en de bijbehorende ASTA maten weergegeven.

\section{Studie 1}

Naast het in kaart brengen van de spontane taal middels de ASTA werd voorheen ook het onderdeel Spontane taalproductie van de Akenste Afasie Test gebruikt (AAT) (Graetz, De Bleser \& Willmes, 1992) om de spontane taal te beoordelen. Middels een 6-punt schaal werd de spontane taal zowel kwalitatief als kwantitatief beoordeeld op 6 verschillende niveaus te weten het communicatief gedrag, de articulatie/prosodie, de geautomatiseerde taal, de semantische structuur, de fonematische structuur en de syntactische structuur. Sinds kort wordt echter in de Logopedische Richtlijn 'Diagnostiek en behandeling van afasie' (Berns et 
Tabel 1: Overzicht van de huidige ASTA maten

\begin{tabular}{lll}
\hline Morfosyntaxis & Semantiek & Fonologie \\
\hline De gemiddelde uitingslengte & $\begin{array}{l}\text { Aantal zelfstandige naamwoor- } \\
\text { den }\end{array}$ & Aantal fonematische parafasieën \\
De finietheidsindex & $\begin{array}{l}\text { Diversiteit zelfstandige naam- } \\
\text { woorden }\end{array}$ & \\
Aantal modalen en koppelwerk- & Aantal lexicale werkwoorden \\
woorden & Diversiteit lexicale werkwoorden \\
Percentage correcte uitingen & Aantal semantische parafasieën \\
Aantal bijzinnen & Aantal neologismen & \\
& & \\
\hline
\end{tabular}

Finietheidsindex: het percentage correcte persoonsvormen gedeeld door het aantal werkwoordsvormen waarbij een persoonsvorm nodig is

al, 2015) aanbevolen om bij voorkeur de Nederlandse editie van de Comprehensive Aphasia Test (CAT-NL) (Visch-Brink, Vandenborre, de Smet \& Mariën, 2014) af te nemen in plaats van de AAT. De CAT-NL kent echter geen testonderdeel waarbij de spontane taal wordt beoordeeld. De analyse van een aantal relevante maten binnen de spontane taal, zoals bijvoorbeeld communicatief gedrag en geautomatiseerde taal, valt weg wanneer er geen gebruik meer wordt gemaakt van het onderdeel Spontane taalproductie van de AAT. Een dergelijke analyse van de spontane taal is niettemin belangrijk aangezien deze analyse een beeld geeft van het communicatieve vermogen van de patiënt. Vanwege bovenstaande ontwikkeling is daarom in de huidige studie een onderzoek gedaan naar de vraag of het een meerwaarde heeft om maten die het communicatief vermogen meten toe te voegen aan de ASTA. Hierbij is gedacht aan de vloeiendheid in het spreken, de gerichtheid van het spreken en geautomatiseerde taal.

Vloeiendheid in het spreken:

Howes (1964) toonde al aan dat het aantal woorden per minuut, ook wel het spreektempo genoemd, een methode is om de vloeiendheid te meten. In de huidige studie is de vloeiendheid van het spreken onderzocht aan de hand van de maten 'woorden exclusief linguïst', 'aantal /eh/', 'pauzes' 'valse starts' en 'onvolledige uitingen'.

Gerichtheid in het spreken:

De meesten patiënten met afasie, ongeacht het type afasie, hebben problemen hebben met het vinden en produceren van woorden (Goodglass \& Wingfield, 1997). Het gevolg hiervan zijn meer haperingen in de taalproductie en meer herhalingen van woorden. Alle mislukte pogingen om te komen tot realisatie van het doelwoord worden in de ASTA weggestreept. Weggestreepte woorden geven aan dat iemand moeite heeft om tot een formulering te komen en niet gericht tot spreken komt. In de huidige studie is onderzoek gedaan of er significant meer woorden moeten worden weggestreept bij mensen met afasie ten opzichte van mensen zonder afasie. Deze maat wordt 'geëexcludeerde woorden' genoemd. Nicholas en Brookshire (1993) en Yorkston en Beukelman (1980) toonden aan dat mensen met afasie verschillen van mensen zonder afasie in de mate van informativiteit en relevantie van de 
antwoorden. De mate van relevantie van de taalproductie geeft informatie over de inhoud van de gesproken taal van de patiënt. Iemand kan veel zeggen, zonder dat dit relevant is of de vraag beantwoordt. In de huidige ASTA bestaat deze maat niet, terwijl het wel essentiële informatie biedt en daarom wordt deze maat eveneens meegenomen in de huidige studie onder de naam 'relevantie antwoord'.

Geautomatiseerde taal:

Ten slotte is het bekend dat mensen met afasie meer geautomatiseerde taal gebruiken dat mensen zonder afasie (Bastiaanse, 2011). Binnen de AAT werd de maat geautomatiseerde taal bekeken door te kijken naar de frequentie van voorkomen van 'taalautomatismen', 'stereotiepen'en 'echolalie'. Met een taalautomatisme wordt een steeds weerkerende, vormvaste uitdrukking bedoeld die niet in de taalcontext past. Een stereotiep is een vormvaste formule die aangepast is aan de spreeksituatie. Echolalieën zijn herhalingen van de woorden van gesprekspartner (Graetz, De Bleser \& Willmes, 1992). Geautomatiseerde taal kan een vertekend beeld geven over de kwaliteit van de communicatie. Het gebruiken van geautomatiseerde uitingen kan namelijk leiden tot een hoog percentage correcte uitingen, zonder dat er sprake is van bewuste grammaticale zinsvorming. Binnen dit onderzoek is gekozen om de taalautomatismen, stereotypen en echolalieën nader te onderzoeken als drie losstaande maten.

\section{Studie 2}

Naast de analyse van de maten voor het communicatieve vermogen is er tevens onderzoek verricht naar de meerwaarde van het toevoegen van extra linguïstische maten aan de ASTA. Scheiden van bestaande gecombineerde maat:

Van der Scheer (2009) geeft in haar onderzoek een aantal aanbevelingen voor verder onderzoek naar de ASTA. Eén van haar aanbevelingen is om de twee werkwoordssoorten in de maat 'aantal koppel- en modale werkwoorden', die op dit moment in de ASTA nog gezamenlijk worden geteld om tot een algemene score te komen, te scheiden van elkaar. Van der Scheer (2009) noemt in haar onderzoek dat deze werkwoordssoorten juist verschillen van elkaar. Beide werkwoordsoorten meten iets anders. Een koppelwerkwoord verbindt het onderwerp aan een naamwoord, terwijl de modale (hulp)werkwoorden informatie geven over de verhouding tussen de beschrijving en de werkelijkheid (Algemene Nederlandse Spraakkunst; ANS). Momenteel is niet inzichtelijk genoeg waar de persoon met afasie moeite mee heeft als hij afwijkend scoort op deze gecombineerde maat. In de huidige studie zijn deze twee maten als twee aparte maten onderzocht om te bekijken of mensen met afasie op deze afzonderlijke maten ook afwijkend scoren, of wellicht op slechts één van de twee.

Voorzetsels:

Een andere maat die in de huidige studie onderzocht is, is het aantal voorzetsels. Friederici (1982) heeft aangetoond dat afasiepatienten syntactische en lexicale voorzetsels anders verwerken en dat deze verwerking kan verschillen tussen de specifieke afasiesyndromen. Het aantal voorzetsels en het type voorzetsel zou iets kunnen zeggen over de lexicale vaardigheid van een afasiepatiënt. Syntactische voorzetsels worden ook wel gezien als een verplicht onderdeel van de zin. Deze voorzetsels zijn ook niet vervangbaar door een ander voorzet- 
sel (Bennis, Prins \& Vermeulen, 1983). Lexicale voorzetsels hebben echter een eigen lexicale betekenis en zijn wel vervangbaar door een ander voorzetsel. In de spontanetaalanalyse valt op dat voorzetsels vaak weggelaten of verkeerd gebruikt worden (Van der Scheer, 2009). Er is daarom gekozen om zowel de syntactische als de lexicale voorzetsels verder te onderzoeken binnen de spontane taal van mensen met afasie.

Inhoudelijke lexicale maten:

Eerder onderzoek naar de productie van bijvoeglijke naamwoorden bij mensen met een afasie toonde tegenstrijdige resultaten. Zo toonden Meltzer-Asscher en Thompson (2014) aan dat agrammatisch sprekende afasiepatiënten evenveel bijvoeglijke naamwoorden gebruiken als de controlegroep, terwijl de Roo et al. (2003) aantoonden dat de controlegroep juist meer gebruik maakte van bijvoeglijke naamwoorden dan de afasiepatiënten. Het extra gebruik maken van bijvoeglijk naamwoorden in de taal zou bijvoorbeeld bij afasie van Broca kunnen voorkomen (Bastiaanse, 2011). Onderbouwd door eerder onderzoek bestaan er mogelijke verschillen in de aantallen bijvoeglijke naamwoorden tussen afasiepatiënten onderling. Nader onderzoek in het gebruik van bijvoeglijke naamwoorden lijkt zinvol. Bastiaanse et al. (1996) beschrijven dat mensen met een afasie wellicht moeite hebben met het generen van bijwoorden in tegenstelling tot gezonde taalsprekers. Dit zou ook het geval zijn bij afasiepatiënten die grammaticaal weinig problemen hebben. Momenteel worden bijwoorden niet meegenomen in de analyse van de ASTA. In deze studie is gekozen om het gebruik van bijwoorden verder te onderzoeken.

\section{Methode}

\section{Proefpersonen}

\section{Studie 1}

Voor deze studie zijn 16 mensen met afasie geïncludeerd. Deze groep bestond uit 11 mannen en 5 vrouwen met een gemiddelde leeftijd van 63.1 jaar. De controlegroep bestond uit 20 niet-taalgestoorde proefpersonen zonder hersenletsel. Deze groep bestond uit 7 mannen en 13 vrouwen met een gemiddelde leeftijd van 55;7 jaar. Er is niet gecontroleerd voor leeftijd, sekse en opleiding in navolging van de bevindingen van het onderzoek door van der Scheer (2009). Zowel de mensen met afasie als de mensen uit de controlegroep hadden het Nederlands als moedertaal. Individuele gegevens van de controlegroep staan in bijlage 1, die van de patiëntengroep staan in tabel 2.

\section{Studie 2}

Voor deze studie zijn 14 mensen met afasie geselecteerd. De groep komt overeen met de groep van studie 1, enkel proefpersoon A8 en proefpersoon A14 zijn niet geselecteerd voor deze studie aangezien zij onvoldoende woorden produceerden voor een betrouwbare linguïstische analyse. De controlegroep bestond uit 40 niet-taalgestoorde proefpersonen zonder 
TOEVOEGING LINGUISTISCHE EN COMMUNICATIEVE MATEN BINNEN DE ASTA 29

Tabel 2: Overzicht van de individuele gegevens van de afasiegroep van studie 1 en 2

\begin{tabular}{|c|c|c|c|c|c|c|c|c|}
\hline $\begin{array}{l}\text { Proef } \\
\text { persoon }\end{array}$ & Geslacht & Leeftijd & $\begin{array}{l}\text { Opleidings } \\
\text { niveau }\end{array}$ & $\begin{array}{l}\text { Handig } \\
\text { heid }\end{array}$ & Etiologie & Afasie & TPO & $\begin{array}{l}\text { Score } \\
\text { TT }\end{array}$ \\
\hline $\mathrm{Al}$ & $\mathrm{M}$ & 51 & $\mathrm{HBO}$ & rechts & ICVA-li & Wernicke & 20 & 44 \\
\hline A2 & M & 74 & WO & rechts & ICVA-li & Broca & 24 & 40 \\
\hline A3 & $\mathrm{V}$ & 68 & $\mathrm{MB}$ & rechts & ICVA-li & amnestisch & 240 & 15 \\
\hline A4 & M & 59 & $\mathrm{MBO}$ & rechts & $\mathrm{SH}$ & rest & 25 & 2 \\
\hline A5 & M & 58 & $\mathrm{MBO}$ & rechts & $\mathrm{SH}$ & amnestisch & 12 & 45 \\
\hline A6 & M & 54 & WO & rechts & ICVA-li & globaal & 8 & 49 \\
\hline A7 & M & 64 & $<\mathrm{MBO}$ & rechts & ICVA-li & amnestisch & 12 & 5 \\
\hline A8 & M & 19 & MBO & rechts & trauma & Broca & 8 & 35 \\
\hline A9 & $\mathrm{V}$ & 75 & $<\mathrm{MBO}$ & rechts & $\mathrm{CC}$ & amnestisch & 12 & - \\
\hline A10 & M & 76 & MBO & rechts & ICVA-li & Wernicke & 3 & 39 \\
\hline Al1 & V & 78 & $<\mathrm{MBO}$ & rechts & ICVA-li & trans. mot. & 3 & - \\
\hline A12 & M & 26 & MBO & rechts & v. men. & amnestisch & 25 & - \\
\hline A13 & M & 83 & $<\mathrm{MBO}$ & rechts & ICVA-li & amnestisch & 2 & 20 \\
\hline A14 & V & 83 & $<\mathrm{MBO}$ & links & ICVA-li & Broca & 4 & 32 \\
\hline A15 & M & 64 & $\mathrm{HBO}$ & rechts & ICVA-li & amnestisch & 4 & - \\
\hline A16 & V & 77 & $<\mathrm{MBO}$ & links & ICVA-li & amnestisch & 6 & - \\
\hline
\end{tabular}

$\mathrm{A}=$ afasiegroep; geslacht $(\mathrm{M}=$ man, $\mathrm{V}=$ vrouw); leeftijd in jaren; opleidingsniveau $(<\mathrm{mbo}=$ lager onderwijs, mbo = middelbaar beroepsonderwijs, hbo = hoger beroepsonderwijs, wo $=$ wetenschappelijk onderwijs); medische diagnose $(\mathrm{CC}=$ contusio cerebri, ICVA $=$ ischemisch cerebrovasculair accident, $\mathrm{SH}=$ subduraal hematoom, v.men. $=$ virale meningitis); T.P.O. $=$ tijd post onset in weken en TT $=$ aantal fouten op de Token test. Trans. Mot $=$ transcorticaal motorische afasie

hersenletsel. De data van deze controlegroep zijn overgenomen uit het onderzoek door van der Scheer (2009).

Voor studie 1 kon deze controlegroep niet gebruikt worden, aangezien er geen audiobestanden meer beschikbaar waren van deze samples. Voor studie 1 werden maten onderzocht die niet geanalyseerd konden worden met enkel een geschreven sample. Vandaar dat er voor studie 1 een geheel nieuwe controlegroep is gebruikt. De controlegroep voor studie 2 bestond uit 19 mannen en 21 vrouwen met een gemiddelde leeftijd van 46 jaar. Ook bij deze studie is niet gecontroleerd voor leeftijd, sekse en opleiding in navolging van de bevindingen van het onderzoek door van der Scheer (2009). Individuele gegevens van de controlegroep staan in bijlage 2 . In tabel 2 staat een overzicht van de geselecteerde mensen met afasie.

\section{Materiaal}

Voor zowel studie 1 als studie 2 zijn spontanetaalsamples verzameld volgens het ASTA-protocol (Boxum et al., 2013). 


\section{Procedure}

Binnen Vogellanden, Centrum voor Revalidatie in Zwolle en binnen het Advies- en behandelcentrum van Zorggroep Noordwest-Veluwe werden patiënten geworven bij wie reeds een afasie was vastgesteld door de behandelend logopedist of klinisch linguïst. De onderzoekers hebben gezamenlijk spontanetaalsamples van zestien mensen met afasie verzameld. De opname van het gesprek vond plaats in het revalidatiecentrum waar de afasiepatiënt in behandeling was. Tijdens de testsituatie waren enkel de afasiepatiënt en één van de onderzoekers aanwezig in de ruimte. De spontanetaalsamples van de controlegroep van studie 1 zijn verzameld door de onderzoeker van studie 1 . De taalsamples zijn bij de desbetreffende persoon thuis afgenomen. Ook tijdens dit gesprek waren enkel de proefpersoon en de onderzoeker aanwezig in de ruimte. Alle spontanetaalsamples zijn getranscribeerd volgens de normen van de ASTA (Boxum et al., 2013).

\section{Data-analyse}

Voor zowel studie 1 als studie 2 was de eerste stap het bepalen van de samplegrootte. Het ASTA-protocol (Boxum et al., 2013) geeft aan dat een sample uit 300 woorden bestaat en dit is in beide onderzoeken opgevolgd. Om te kunnen onderzoeken wat de meerwaarde is van het toevoegen van nieuwe maten aan het huidige protocol is er gekozen om de maten te analyseren die beschreven staan in tabel 3.

Tabel 3: Overzicht van de maten die onderzocht zijn in beide studies

\begin{tabular}{ll}
\hline Maten uit studie 1 & Maten uit studie 2 \\
\hline Spreektempo (exclusief onderzoeker) & Aantal koppelwerkwoorden \\
Aantal /eh/ & Aantal modale (hulp)werkwoorden \\
Aantal pauzes & Aantal syntactische voorzetsels \\
Aantal valse starts & Aantal lexicale voorzetsels \\
Aantal onvolledige uitingen & Aantal bijvoeglijke naamwoorden \\
Aantal geëxcludeerde woorden & Aantal bijwoorden \\
Relevantie antwoord & \\
Aantal taalautomatismen & \\
Aantal stereotypen & \\
Aantal echolalieën & \\
\hline \multicolumn{2}{c}{ Relevantie antwoord: Aantal relevante antwoorden van de proefpersoon gedeeld door het aantal gestelde vragen }
\end{tabular}

\section{Maten binnen studie 1}

Vermeulen en Bastiaanse (1984) en Saffran, Berndt en Schwartz (1989) evalueerden het spreektempo op basis van het aantal woorden per minuut. Om het spreektempo in de huidige stu- 
die te kunnen vergelijken met het spreektempo uit bovenstaande literatuur wordt de tijd tot 300 woorden omgezet naar het aantal woorden per minuut. De metingen van het spreektempo zullen exclusief de woorden van de onderzoeker berekend worden. Het aantal pauzes, de interjectie van het opvulwoord /eh/ en het aantal valse starts worden geteld in alle samples. Een pauze wordt geteld wanneer een moment van stilte niet wordt ingevuld door /eh/. Een valse start wordt geteld als minder dan $50 \%$ van het aantal fonemen van het doelwoord is gerealiseerd. Bijvoorbeeld: po politie, waarbij het aantal herhalingen 0 is, maar het aantal valse starts 1 . Een uiting wordt als onvolledig geteld als de spreker zijn poging tot het maken van een uiting opgeeft.

Daarnaast wordt het aantal geëxcludeerde woorden onderzocht. Om de gemiddelde uitingslengte te bepalen worden er binnen de uitingen vaak woorden geëxcludeerd. In dit onderzoek worden deze weggestreepte woorden geteld binnen het spontanetaalsample van de ASTA. Interjecties en deels onverstaanbare uitingen worden niet meegeteld. Onder het aantal geëxcludeerde woorden worden alle ja/nee, alle herhalingen, alle valse starts en alle andere woorden die de uiting ongrammaticaal maken verstaan.

Het aantal vragen, gesteld door de logopedist of linguïst, wordt geteld om de relevantie van de antwoorden te kunnen onderzoeken. Vervolgens wordt geteld hoeveel van deze vragen relevant beantwoord worden door de proefpersoon. Hiervoor is het belangrijk dat de beoordelaar van het spontanetaalsample over genoeg persoonlijke informatie van de proefpersoon beschikt om de gegeven antwoorden te kunnen beoordelen op relevantie. Er wordt dus bekeken of het antwoord qua onderwerp aansluit bij de gestelde vraag en of de gegeven informatie klopt (of worden er wellicht onbedoelde semantische parafasieën gegeven). Van het aantal beantwoorde vragen wordt een ratio berekend. Deze ratio wordt berekend door het aantal relevante gegeven antwoorden te delen door het aantal gestelde vragen.

Alle voorkomens van taalautomatismen, stereotypen en echolalieën worden geteld binnen het sample van 300 woorden.

\section{Maten binnen studie 2}

In dit onderzoek is er onderscheid gemaakt tussen koppelwerkwoorden en modale (hulp)werkwoorden omdat deze soorten werkwoorden een andere verhouding uitdrukken (Van der Scheer, 2009). Dit betekent dat de modale (hulp)werkwoorden en de koppelwerkwoorden apart van elkaar geteld worden. Alle voorkomens van syntactische en lexicale voorzetsels worden geteld.

Daarnaast zijn bijvoeglijke naamwoorden en bijwoorden geteld binnen het spontanetaalsample. Er is hierbij geen onderscheid gemaakt tussen verschillende soorten bijvoeglijke naamwoorden of bijwoorden. 


\section{Resultaten}

\section{Studie 1}

\section{Beschrijvende statistiek}

Voorafgaand aan alle analyses is er een Kolmorgorov-Smirnov test uitgevoerd om de normaliteit van alle data te kunnen bepalen. In tabel 4 staat de beschrijvende statistiek van beide groepen beschreven.

Tabel 4: Minimale en maximale score en mediaan voor de afasiegroep en de controlegroep voor de maten uit onderzoek 1

\begin{tabular}{lllll}
\hline Maten & Min. & Max. & Mediaan & KS-test \\
\hline Afasiegroep & & & & \\
Spreektempo in woorden & 33.3 & 151.3 & 90.4 & $.20^{*}$ \\
Aantal /eh/ & 5 & 117 & 28 & $.11^{*}$ \\
Aantal pauzes & 0 & 31 & 4 & .00 \\
Aantal valse starts & 1 & 10 & 5 & $.51^{*}$ \\
Aantal onvol. uitingen & 0 & 13 & 2,5 & .01 \\
Aantal geëexcl. woorden & 23 & 135 & 50 & $.07^{*}$ \\
Relevantie antwoorden & 0,7 & 1 & 0,9 & .01 \\
Aantal taalautomatismen & 0 & 0 & 0 & - \\
Aantal stereotypen & 0 & 15 & 0 & .00 \\
Aantal echolalieën & 0 & 1 & 0 & .00 \\
\hline Controlegroep & & & & \\
Spreektempo in woorden & 102.9 & 173.1 & 131.4 & $.20^{*}$ \\
Aantal /eh/ & 3 & 36 & 17 & $.20^{*}$ \\
Aantal pauzes & 0 & 2 & 0 & .00 \\
Aantal valse starts & 0 & 3 & 0 & .00 \\
Aantal onvol. uitingen & 0 & 7 & 1 & .00 \\
Aantal geëexcl. woorden & 10 & 42 & 23 & $.16^{*}$ \\
Relevantie antwoorden & 1 & 1 & 1 & - \\
Aantal taalautomatismen & 0 & 0 & 0 & - \\
Aantal stereotypen & 0 & 0 & 0 & - \\
Aantal echolalieën & 0 & 0 & 0 & - \\
\hline \multicolumn{1}{c}{ Min. = laagste score; max. = hoogste score; ${ }^{*}=$ data normaal verdeeld, KS-test = Kolmgorov-Smirnov test; } \\
geëxcl.= geëxludeerde; onvol. = onvolledige; - = geen verdere analyse mogelijk vanwege maximale score
\end{tabular}

De Kolmgorov-Smirnov test toonde aan dat er bij een groot aantal variabelen sprake was van een niet normale verdeling. Om deze reden is vervolgens de Mann Whitney gebruikt. Met behulp van de Mann Whitney U test is onderzocht of er verschillen zijn tussen de afasiegroep en de controlegroep op de verschillende maten. Hieruit bleek dat de patiëntengroep 
significant slechter presteerde op de maten 'spreektempo' ( $U=44.0, p<.001$ ), 'aantal pauzes' $(U=39.0, p<.001)$, 'aantal valse starts' $(U=27.0, p<.001)$, 'aantal onvolledige uitingen' ( $U=90.0, p=.023)$ 'aantal geëxcludeerde woorden' $(U=22.0, p<.001)$ en 'relevantie antwoord' $(U=70.0, p<.001)$, ten opzichte van de controlegroep. Bij de maat 'hoeveelheid /eh/' nadert het verschil de significantie $(U=100.5, p=.058)$. In tabel 5 staat een overzicht van de significante verschillen weergegeven. In de controlegroep wordt door geen enkele persoon een echolalie of taalautomatisme geproduceerd. Binnen de afasiegroep komen ook geen taalautomatismen voor en slechts 1 keer een echolalie. Daarom is er voor deze maten geen statistiek toegepast. Binnen de patiëntengroep kwamen in tegenstelling tot in de controlegroep wel stereotypen voor. Hierop kan geconcludeerd worden dat zij significant slechter presteerden op deze maat ten opzichte van de controlegroep $(U=110.0, p=.008)$.

Tabel 5: Resultaten van de Mann-Whitney U tests over de scores van de afasiegroep ten opzichte van de controlegroep van studie 1 .

\begin{tabular}{lll}
\hline Maten & $\boldsymbol{U}$-waarde & $\boldsymbol{p}$-waarde \\
\hline Spreektempo & 44.0 & $<.01^{*}$ \\
Aantal /eh/ & 100.5 & $=.06$ \\
Aantal pauzes & 39.0 & $<.01^{*}$ \\
Aantal valse starts & 27.0 & $<.01^{*}$ \\
Aantal onvolledige uitingen & 90.0 & $=.02^{*}$ \\
Aantal geëxcludeerde woorden & 22.0 & $<.01^{*}$ \\
Relevantie antwoord & 70.0 & $<.01^{*}$ \\
Aantal stereotypen & 110.0 & $=.01^{*}$ \\
\hline
\end{tabular}

\section{Studie 2}

Beschrijvende statistiek

Voorafgaand aan de analyses is er een Kolmogorov-Smirnov test uitgevoerd om te analyseren of de data normaal verdeeld waren. Verdere descriptieve gegevens van beide groepen staan in tabel 6 weergegeven.

De resultaten van de Kolmogorov-Smirnov test toonden aan dat een groot aantal variabelen niet normaal verdeeld was. Er is daarom gekozen om vervolgens een Mann-Whitney $\mathrm{U}$ test uit te voeren om een vergelijking te kunnen maken tussen de afasiegroep en de controlegroep. Uit deze test blijkt dat de afasiegroep significant minder bijvoeglijke naamwoorden $(U=40.0, \mathrm{p}=<0.001)$ en koppelwerkwoorden $(U=153.5, p=.012)$ produceert dan de controlegroep. Een gelijk aantal modale (hulp)werkwoorden wordt geproduceerd in beide groepen. Er worden geen significante verschillen gevonden op het aantal bijwoorden, aantal syntactische voorzetsels en aantal lexicale voorzetsels. In tabel 7 is een overzicht van de 
Tabel 6: Minimale en maximale score en mediaan voor de afasiegroep en de controlegroep voor de maten uit onderzoek 2

\begin{tabular}{lllll}
\hline Maten & Min. & Max. & Mediaan & KS-test \\
\hline Afasiegroep & & & & \\
Aantal koppelwerkwoorden & 0 & 8 & 5.1 & $.20^{*}$ \\
Aantal modale (hulp)werkwoorden & 1 & 10 & 4.4 & .03 \\
Aantal syntactische voorzetsels & 0 & 21 & 3.9 & .00 \\
Aantal lexicale voorzetsels & 3 & 46 & 19.1 & .03 \\
Aantal bijvoeglijke naamwoorden & 0 & 7 & 3.3 & $.14^{*}$ \\
Aantal bijwoorden & 4 & 34 & 19.3 & $.20^{*}$ \\
\hline Controlegroep & & & & \\
Aantal koppelwerkwoorden & 1 & 14 & 7.6 & $.08^{*}$ \\
Aantal modale (hulp)werkwoorden & 0 & 11 & 3.9 & .02 \\
Aantal syntactische voorzetsels & 0 & 7 & 2.2 & .00 \\
Aantal lexicale voorzetsels & 10 & 29 & 20.6 & .03 \\
Aantal bijvoeglijke naamwoorden & 3 & 22 & 9.0 & $.11^{*}$ \\
Aantal bijwoorden & 8 & 36 & 20.3 & $.14^{*}$ \\
\hline \multicolumn{1}{c}{ Min. = laagste score; max = hoogste score; ${ }^{*}=$ data normaal verdeeld; KS-test $=$ Kolmgorov-Smirnov test }
\end{tabular}

scores op de Mann-Whitney U test weergegeven.

Tabel 7: Resultaten van de Mann-Whitney U tests over de scores van de afasiegroep ten opzichte van de controlegroep van studie 2

\begin{tabular}{lll}
\hline Maten & $\begin{array}{l}\boldsymbol{U} \text { - } \\
\text { waarde }\end{array}$ & $\begin{array}{l}\boldsymbol{p} \text { - } \\
\text { waarde }\end{array}$ \\
\hline Aantal koppelwerkwoorden & 153.5 & $=.01^{*}$ \\
Aantal modale (hulp)werkwoorden & 270.5 & $=.85$ \\
Aantal syntactische voorzetsels & 237.0 & $=.39$ \\
Aantal lexicale voorzetsels & 221.0 & $=.24$ \\
Aantal bijvoeglijke naamwoorden & 40.0 & $<.01^{*}$ \\
Aantal bijwoorden & 253.5 & $=.60$ \\
\hline
\end{tabular}


TOEVOEGING LINGUISTISCHE EN COMMUNICATIEVE MATEN BINNEN DE ASTA 35

\section{Conclusie}

De ASTA is een standaard voor de analyse van de spontane taal in Nederland. De huidige ASTA bestaat uit twaalf taalmaten. Op basis van deze maten kan er een uitspraak worden gedaan over de fonematische, lexicaal-semantische en de morfosyntactische vaardigheden van afasiepatiënten (Bastiaanse, 2011). De onderhavige studies beoogden te onderzoeken in hoeverre zestien nieuwe taalmaten een waardevolle toevoeging zijn op de huidige ASTA. Middels groepsvergelijkingen tussen spontanetaalsamples van mensen zonder afasie en mensen met afasie zijn de nieuwe taalmaten in kaart gebracht. De uitgevoerde groepsvergelijkingen met de nieuwe maten tonen aan dat mensen met afasie significant afwijkend scoren op de maten 'spreektempo (bij de personen met afasie berekend exclusief de woorden van de linguïst in woorden per minuut)', 'aantal pauzes', 'aantal valse starts', 'aantal onvolledige uitingen, 'aantal geëxcludeerde woorden', 'relevantie antwoord', 'aantal stereotypen', 'aantal koppelwerkwoorden' en 'aantal bijvoeglijke naamwoorden' ten opzichte van de controlegroep. Er worden geen significante verschillen gevonden op de maten 'aantal /eh/', 'taalautomatismen', 'echolalieën', 'modale (hulp)werkwoorden', 'syntactische voorzetsels', 'lexicale voorzetsels' en 'bijwoorden'.

\section{Discussie}

Van de onderzochte zestien maten blijkt de groep met afasiepatiënten op negen maten significant slechter te scoren. Hieronder wordt ingegaan of deze negen maten daadwerkelijk klinisch relevant zijn om toe te voegen aan de al bestaande ASTA maten.

De huidige ASTA voorziet nog niet in het wel of niet vaststellen of de afasie vloeiend of niet vloeiend is. Momenteel gebeurt deze indeling op basis van het klinisch oordeel van de linguïst. Het zou zuiverder zijn als dit middels een specifieke maat binnen de ASTA ook vast te stellen is. Voor het in kaart brengen van de vloeiendheid van de afasie zijn in studie 1 maar liefst vijf maten onderzocht ('spreektempo', 'aantal /eh/', 'aantal pauzes', 'aantal valse starts' en 'onvolledige uitingen'). Alleen op de maat 'aantal /eh/' scoren de patiënten met afasie hetzelfde als de controlegroep. Voor de bruikbaarheid en de beperkte tijd van de klinisch linguïst is het goed om te kijken of er met minder dan deze vier maten ook een adequaat beeld gegeven kan worden van de vloeiendheid. Het aantal pauzemomenten kan gezien worden als een subjectieve, niet eenduidige maat: wat de ene klinische linguïst als een pauze telt kan de andere nog een geaccepteerd moment tussen twee woorden vinden. De maat 'aantal pauzes' kan pas een objectieve maat zijn als er afspraken zijn over de duur gemeten in seconden. De maat 'woorden exclusief linguïst' is een zeer tijdrovende maat aangezien alle spreektijden van de linguïst geklokt moeten worden en afgetrokken worden van de totaaltijd. Om bovenstaande redenen kan er gekozen worden om de vloeiendheid enkel te bepalen door het aantal valse starts en het aantal onvolledige uitingen te tellen.

De ASTA biedt inzicht in het lexicale, fonologische en syntactische functioneren, maar niet of de talige inhoud kloppend is. Voor een completer beeld over de manier waarop een persoon met afasie spreekt, zou het een goede aanvulling zijn als hier ook een maat voor 
is. Door het toevoegen van de maat 'relevantie van het antwoord' kan dit nu wel inzichtelijk gemaakt worden. Middels de maat 'geëxcludeerde woorden' kan nu objectief vastgesteld worden of een persoon met afasie inderdaad minder snel tot formuleren komt. Voor meer informatie rondom geautomatiseerde taal blijkt dat de maat 'stereotypen' voldoende is. Beide maten zijn een waardevolle toevoeging op de huidige maten.

Ten slotte wordt er geadviseerd om in navolging van Van der Scheer (2009) om de maat 'koppelwerkwoorden' als een op zichzelf staande maat op te nemen in de ASTA en de maat 'modalen' te laten vervallen. De bestaande maat geeft nu mogelijk een vertekend beeld, aangezien er geen significante verschillen gevonden zijn tussen de controlegroep en de afasiegroep op het aantal modalen. Ook is het taalkundig gezien juister om maten niet samen te voegen. Het uiteindelijke aantal is in de huidige ASTA een gedeeld aantal en zegt daardoor te weinig over de twee maten afzonderlijk.

De maat 'bijvoeglijk naamwoorden' zou gebruikt kunnen worden als bij een lichte afasie of restafasie geen afwijkingen gevonden worden in de maten zelfstandige naamwoorden en lexicale werkwoorden, maar iemand toch klaagt over woordvindingsproblemen en moeite heeft met gedetailleerd vertellen.

Het geeft inzicht dat afasiepatiënten niet afwijkend scoren op de maten 'eh', 'taalautomatismen', 'echolalieën', 'modale hulpwerkwoorden', 'syntactische voorzetsels', 'lexicale voorzetsels', en 'bijwoorden'. Zij produceren deze in dezelfde mate als gezonde taalsprekers. Deze maten leveren dus geen meerwaarde op in het in kaart brengen van fatische taal.

Van bovenstaande zeven maten kunnen er zes gezien worden als optionele maten, die aanvullend op de al bestaande maten van de ASTA ingezet kunnen worden door de klinische linguïst. De maat koppelwerkwoorden zou de bestaande gecombineerde maat 'koppelwerkwoorden en modale (hulp) werkwoorden' kunnen vervangen. De nieuwe taalmaten zijn van toegevoegde waarde om de gevolgen van afasie completer in beeld te brengen. Bij elke afasiepatiëent kan afhankelijk van de hulpvraag en het beeld gekozen worden om extra taalmaten te bekijken. Op deze manier kunnen goede aanknopingspunten voor vervolgonderzoek en therapie gegeven worden.

\section{Aanbevelingen}

De groep met afasiepatiënten bestond uit meer vloeiend sprekende afasiepatiënten (10) dan niet vloeiende (6). Mogelijk zijn resultaten hierdoor beïnvloed. Voor vervolgonderzoek wordt daarom aanbevolen om de groep met afasiepatiënten gelijk te verdelen. Op basis van de huidige studies is het aan te bevelen om een aantal nieuwe maten toe te voegen aan het huidige ASTA-protocol, als een optionele set waaruit de klinisch linguïst kan kiezen. Van de zestien onderzochte maten, blijken er bij negen maten daadwerkelijk significante verschillen te zijn tussen de mensen met afasie en de gezonde taalsprekers. Uiteindelijk concluderen de onderzoekers dat hiervan zeven maten klinisch relevant zijn ten opzichte van de al bestaande ASTA maten. Het betreft de maten: 'valse starts', 'onvolledige uitingen', 'geëxcludeerde woorden', 'relevantie van het antwoord', 'stereotypen', 'koppelwerkwoorden' en 'bijvoeglijke naamwoorden'. De toevoeging van bovenstaande maten levert een bijdrage aan 
TOEVOEGING LINGUISTISCHE EN COMMUNICATIEVE MATEN BINNEN DE ASTA 37

de kwaliteit van de beoordelingen van de spontane taal en daarmee aan de onderliggende stoornis(sen) bij de patiënten met afasie en geven richting aan eventueel vervolgonderzoek.

\section{Referenties}

Algemene Nederlandse Spraakkunst (ANS). Elektronische Algemene Nederlandse Spraakkunst (ANS). http://ans.ruhosting.nl/e-ans/.

Bastiaanse, R., Edwards, S., \& Kiss, K. (1996). Fluent aphasia in three languages: aspects of spontaneous speech. Aphasiology, 10(6), 561-575.

Bastiaanse, R. (2011). Afasie. Bohn Stafleu van Loghum

Bennis, H., Prins, R., \& Vermeulen, J. (1983). Lexical-semantic versus syntactic disorders in aphasia: the processing of prepositions. Publikaties van het instituut voor algemene taalwetenschap.

Berns, P.E.G., Jünger, H., Boxum, E., Nouwens, F., van der Staaij., van Wessel., van Dun, W., van Lonkhuijsen, J.G., \& CBO. (2015). Logopedische Richtlijn 'Diagnostiek en behandeling van afasie'. Woerden: Nederlandse Vereniging voor Logopedie en Foniatrie.

Boxum, E., Van der Scheer, F. \& Zwaga, M. (2013). Analyse voor spontane taal; standaard in samenspraak met de VKL. Zwolle: Vereniging voor Klinische Linguïstiek.

De Roo, E., Kolk, H., \& Hofstede, B. (2003). Structural properties of syntactically reduced speech: a comparison of normal speakers and Broca's aphasics. Brain and Language, $86,99-115$.

Friederici, A. (1982). Syntactic and semantic processes in aphasic deficits: the availability of prepositions. Brain and Language, 249-258.

Goodglass, H., \& Wingfield, A. (1997). Anomia: Neuroanatomical and cognitive correlates. New York: Academic press. p.4

Graetz, P., De Bleser, R., \& Willmes, K. (1992). Akense Afasietest. Lisse: Swets \& Zeitlinger

Howes, D. (1964). Application of the word-frequency concept to aphasia. In A.V.S. de Reuck en M. O'Connor (Eds). Disorders of Language (London: J. \& A. Churchill), pp 47-78.

Meltzer-Asscher, A., \& Thompson, C.K. (2014). The forgotten grammatical category: Adjective use in agrammatic aphasia. Journal of Neurolinguistics, 30, 46-68.

Nicholas, L.E., \& Brookshire, R.H. (1993). A system for quantifying the informativeness and efficiency of the connected speech of adults with aphasia. Journal of Speech and Hearing Research, 36, 338-350.

Prins, R., \& Bastiaanse, R. (2004). Review: Analysing the spontaneous speech of aphasic speakers. Aphasiology, 18, 1075-1091.

Saffran, E.M., Berndt, R.S., \& Schwartz, M.F. (1989). The Quantitative Analysis of Agrammatic Production: Procedure and Data. Brain and language, 37, 440-479.

Van der Scheer, F. (2009). De invloed van geslacht, leeftijd en opleidingsniveau op verschillende kwantitatieve maten binnen een spontane taalsample. Masterscriptie, Rijksuniversiteit Groningen.

Vermeulen, J. \& Bastiaanse, R. (1984). Stoornissen in de spontane taal bij afasiepatiënten. Rapport voor de Stichting Afasie Nederland. 
Visch-Brink, E., Vandenborre, D., de Smet, H.J., \& Mariën, P. (2014). CAT-NL: Comprehensive Aphasia Test, Nederlandse editie. Pearson.

Yorkston, K. M., \& Beukelman, D. R. (1980). An analysis of connected speech samples of aphasic and normal speakers. Journal of Speech and Hearing Disorders, 45, 27-36. 


\section{Bijlage 1: Overzicht van individuele gegevens van de con- trolegroep van studie 1}

\begin{tabular}{lllll}
\hline Proefpersoon & Geslacht & Leeftijd & Opleidingsniveau & Handigheid \\
\hline 1 & V & 57 & MBO & rechts \\
2 & V & 48 & MBO & links \\
3 & M & 56 & HBO & links \\
4 & V & 55 & MBO & links \\
5 & V & 59 & MBO & rechts \\
6 & V & 54 & HBO & rechts \\
7 & M & 49 & MBO & rechts \\
8 & V & 51 & HBO & rechts \\
9 & M & 68 & WO & rechts \\
10 & V & 57 & $<$ MBO & rechts \\
11 & V & 49 & MBO & rechts \\
12 & V & 66 & $<$ MBO & rechts \\
13 & M & 68 & MBO & rechts \\
14 & M & 49 & MBO & rechts \\
15 & V & 63 & $<$ MBO & rechts \\
16 & M & 63 & MBO & links \\
17 & V & 43 & MBO & rechts \\
18 & V & 47 & HBO & rechts \\
19 & V & 50 & MBO & rechts \\
20 & M & 62 & WO & rechts \\
\hline
\end{tabular}

Geslacht ( $\mathrm{M}=$ man, $\mathrm{V}=$ vrouw); leeftijd in jaren, opleidingsniveau $(<\mathrm{mbo}=$ lager onderwijs, mbo = middelbaar beroepsonderwijs, hbo = hoger beroepsonderwijs, wo $=$ wetenschappelijk onderwijs) 


\section{Bijlage 2: Overzicht van individuele gegevens van de con- trolegroep van studie 2}

\begin{tabular}{|c|c|c|c|}
\hline Proefpersoon & Geslacht & Leeftijd & Opleidingsniveau \\
\hline 1 & $\mathrm{~V}$ & 53 & $\mathrm{HBO}$ \\
\hline 2 & $\mathrm{~V}$ & 50 & WO \\
\hline 3 & $\mathrm{~V}$ & 32 & wo \\
\hline 4 & $\mathrm{~V}$ & 18 & MBO \\
\hline 5 & M & 21 & $<\mathrm{MBO}$ \\
\hline 6 & $\mathrm{M}$ & 20 & MBO \\
\hline 7 & M & 40 & MBO \\
\hline 8 & M & 46 & $\mathrm{HBO}$ \\
\hline 9 & M & 48 & $\mathrm{HBO}$ \\
\hline 10 & $\mathrm{~V}$ & 58 & $<\mathrm{MBO}$ \\
\hline 11 & M & 54 & $<\mathrm{MBO}$ \\
\hline 12 & M & 59 & HBO \\
\hline 13 & $\mathrm{~V}$ & 56 & $<\mathrm{MBO}$ \\
\hline 14 & $\mathrm{M}$ & 58 & MBO \\
\hline 15 & $\mathrm{~V}$ & 45 & MBO \\
\hline 16 & M & 78 & $<\mathrm{MBO}$ \\
\hline 17 & M & 52 & $<\mathrm{MBO}$ \\
\hline 18 & M & 39 & MBO \\
\hline 19 & $\mathrm{~V}$ & 53 & MBO \\
\hline 20 & $\mathrm{~V}$ & 29 & MBO \\
\hline 21 & $\mathrm{~V}$ & 44 & $<\mathrm{MBO}$ \\
\hline 22 & $\mathrm{~V}$ & 84 & $\mathrm{HBO}$ \\
\hline 23 & $\mathrm{~V}$ & 58 & WO \\
\hline 24 & $\mathrm{~V}$ & 60 & $\mathrm{HBO}$ \\
\hline 25 & $\mathrm{~V}$ & 59 & $\mathrm{HBO}$ \\
\hline 26 & $\mathrm{~V}$ & 24 & HBO \\
\hline 27 & $\mathrm{~V}$ & 27 & MBO \\
\hline 28 & $\mathrm{~V}$ & 41 & $\mathrm{HBO}$ \\
\hline 29 & $\mathrm{~V}$ & 36 & $<\mathrm{MBO}$ \\
\hline 30 & M & 56 & $\mathrm{HBO}$ \\
\hline 31 & $\mathrm{M}$ & 64 & MBO \\
\hline 32 & $\mathrm{~V}$ & 29 & MBO \\
\hline 33 & $\mathrm{~V}$ & 62 & $<\mathrm{MBO}$ \\
\hline 34 & $\mathrm{~V}$ & 56 & $<\mathrm{MBO}$ \\
\hline 35 & $\mathrm{M}$ & 39 & HBO \\
\hline 36 & M & 23 & MBO \\
\hline 37 & $\mathrm{~V}$ & 56 & MBO \\
\hline 38 & M & 22 & $\mathrm{HBO}$ \\
\hline 39 & $\mathrm{~V}$ & 53 & $<\mathrm{MBO}$ \\
\hline 40 & M & 50 & $<\mathrm{MBO}$ \\
\hline
\end{tabular}

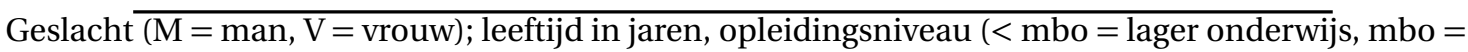
middelbaar beroepsonderwijs, hbo $=$ hoger beroepsonderwijs, wo $=$ wetenschappelijk onderwijs) 